\title{
Mutations that alter both localization and production of a yeast nuclear protein
}

\author{
Pamela A. Silver, ${ }^{1}$ Annette Chiang, and Ingrid Sadler \\ Department of Biology, Princeton University, Princeton, New Jersey 08544 USA
}

\begin{abstract}
The first $\mathbf{7 4}$ amino acids of the yeast GAL4 gene product are sufficient to localize a GAL4- $\beta$-galactosidase chimeric protein to the yeast nucleus. Chimeric proteins missing the first 74 GAL4 amino acids, but containing almost all of the rest of GAL4, are not localized to the nucleus and are expressed at higher levels than their nuclear counterparts. On this basis, point mutations within $G A L 4$, which reduce nuclear localization and increase production of a normally nuclear GAL4- $\beta$-galactosidase fusion protein, were isolated and sequenced. The effect of these mutations on the localization and expression of the intact GAL4 protein was examined. The degree to which the mutant proteins are excluded from the nucleus varies, but all mutations cause overproduction of the protein. Point mutations altering two of the six cysteine residues of the GAL4 putative 'zinc finger' abolish gene activation by intact GAL4; however, mutations in nearby residues have no effect on GAL4-dependent gene activation.
\end{abstract}

[Key Words: GAL4; nuclear targeting; zinc fingers; protein localization]

Received June 30, 1987; revised version accepted April 18, 1988.

Nuclear proteins contain stretches of amino acids responsible for their localization to the nucleus (for review, see Silver and Hall 1988). At least two consensus nuclear targeting sequences have been proposed (Hall et al. 1984; Kalderon et al. 1984). Affinity for DNA alone appears to be neither necessary nor sufficient for nuclear protein targeting (Paucha et al. 1985; Silver et al. 1986), arguing that proteins do not enter the nucleus by diffusion through the pore and remain due to interactions with DNA. Instead, recent studies indicate that nuclear protein uptake is a saturable process and can be competed by an excess of a specific nuclear targeting peptide (Goldfarb et al. 1986; Lanford et al. 1986). These results suggest that nuclear protein uptake is a receptor-mediated process.

By using gene fusions, we have previously shown that the first 74 amino acids of the GAL4-gene product are sufficient to localize a GAL4- $\beta$-galactosidase chimeric protein to the nucleus of the yeast Saccharomyces cerevisiae (Silver et al. 1984). The GAL4-gene product is an 881-amino-acid DNA-binding protein (Laughon and Gesteland 1982; Giniger et al. 1985) that activates the genes involved in galactose metabolism (Douglas and Hawthorne 1972; St. John and Davis 1981). The information for specific DNA binding is also contained in the first 74 GAL4 amino acids (Keegan et al. 1986). However, substitution of the first 74 GAL4 amino acids with a prokaryotic DNA-binding protein does not result in nuclear localization (Silver et al. 1986). Moreover, a chimeric protein containing GAL4 amino acids $79-752$ fused to $\beta$-galactosidase is excluded from the nucleus, demonstrating that the first 74 GAL4 amino acids are

\footnotetext{
${ }^{1}$ Corresponding author.
}

also necessary for nuclear localization. We also observed that nonnuclear GAL4- $\beta$-galactosidase fusion proteins were produced at levels 10 -fold higher when compared to nuclear GAL4- $\beta$-galactosidase proteins (Silver et al. 1984).

We now report the isolation and characterization of a new class of GAL4-linked point mutations that affect both the production and the nuclear localization of a chimeric GAL4- $\beta$-galactosidase and intact GAL4 protein.

Results

Identification of single amino acid changes in GAL4

We have isolated mutations within the GAL4 segment of a GAL4-lacZ hybrid gene that lead to the overexpression of this gene fusion. A plasmid carrying the gene fusion encoding the first 74 GAL4 amino acids fused to almost all of Escherichia coli $\beta$-galactosidase (Fig. 1) was mutagenized and introduced into yeast, and transformant colonies were screened for their levels of $\beta$-galactosidase expression on X-gal indicator plates (for details of the mutagenesis, see Materials and methods). A number of mutants were identified that expressed elevated levels of $\beta$-galactosidase (Table 1). All those linked to the plasmid involved amino acid changes within the GAL4 segment of the plasmid and were identified by DNA sequencing.

\section{Mutations affect nuclear localization of GAL4- $\beta$ -} galactosidase

Fusion of the first 74 GAL4 amino acids to $\beta$-galactosi- 


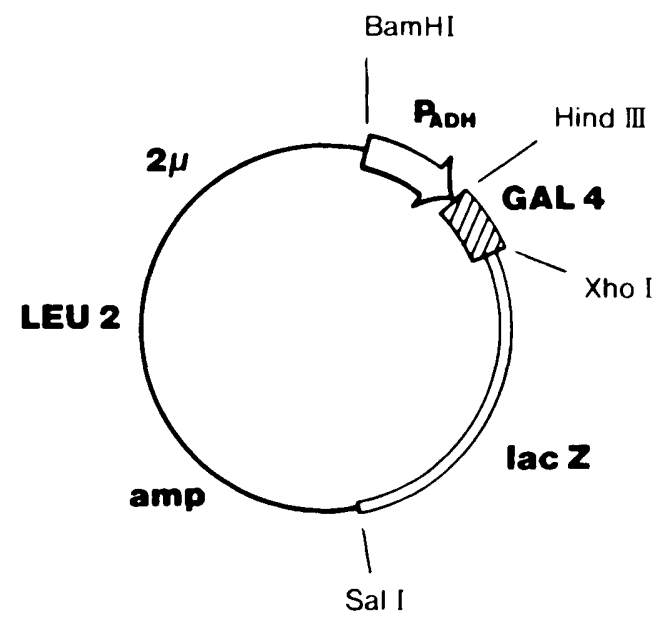

Figure 1. Diagram of plasmid PS118 containing the GAL4$l a c Z$ gene fusion under the control of the $A D H 1$ promoter $\left(\mathrm{P}_{\mathrm{ADH}}\right)$ (open arrow). DNA encoding the first 74 amino acids of GAL4 is contained between the HindIII and Xhol sites. The truncated GAL4 gene was ligated to $l a c Z$ (open line) at a site corresponding to amino acid 7 of $\beta$-galactosidase (Silver et al. 1984). The $A D H-G A L 4-1 a c Z$ gene fusion is contained between the BamHI and Sall sites of the yeast $2-\mu \mathrm{m}$ vector YEp213 (Sherman et al. 1983).

dase results in complete nuclear localization of $\beta$-galactosidase as determined by immunofluorescence (Fig. $2 \mathrm{~A}-\mathrm{C}$; Silver et al. 1984). On the other hand, intact $\beta$ galactosidase is not localized to any intracellular compartment when subjected to a similar analysis (Fig. 2D-E; Moreland et al. 1987).

Mutations causing increased expression of GAL4- $\beta$ galactosidase also affect the degree of nuclear localization of the protein to varying degrees. Cells expressing mutant forms of GAL4- $\beta$-galactosidase were inspected by immunofluorescence with anti- $\beta$-galactosidase antibodies. The patterns of immunofluorescence differed for each mutant protein. However, two general types of staining patterns with respect to the nucleus were observed. Conversion of serine 6 to phenylalanine resulted in the first and most extreme pattern of staining (Fig. $2 \mathrm{~F}-\mathrm{G}$ ); there was almost a complete failure of the GAL4- $\beta$-galactosidase to be specifically nuclear localized. Instead, the immunofluorescence appeared throughout the cell and somewhat concentrated at the cell periphery. The remaining eight mutant proteins gave staining patterns of the second general type; the hybrid protein appeared partly concentrated in the nucleus but also appeared in nonnuclear 'cytoplasmic' locations. The degree to which nonnuclear immunofluorescent material was observed varied among the different mutants. Conversion of cysteine 38 to serine gave the weakest phenotype (Fig. 2N,O). Immunofluorescent material was in the nucleus, although there was some slight cytoplasmic staining and a small 'dot' of very concentrated staining at the nuclear periphery (Fig. $2 \mathrm{~N}$ ). This apparent accumulation of protein at the nuclear periphery was a common feature of localization of proteins with amino acid changes at lysine 20 (Fig. 2J,K), cysteine 21 (Fig. 2L,M), tyrosine 40 (Fig. 2P,Q), and lysine 43 (Fig. $2 \mathrm{R}, \mathrm{S}$ ). In addition to the somewhat granular staining observed in the cytoplasm of cells in the second category (Fig. 2H,J,L,P, R, T, V), larger accumulations of nonnuclear immunofluorescent material were observed for cells producing GAL4- $\beta$-galactosidase with arginine 51 converted to glycine (Fig. 2V,W).

\section{Mutations in GAL4 result in overproduction of GAL4- $\beta$-galactosidase protein}

The nine amino acid changes in GAL4 led to increased levels of GAL4- $\beta$-galactosidase, as determined by $\beta$-galactosidase assays (Table 1). Cells producing normal GAL4- $\beta$-galactosidase from a multicopy plasmid yielded 35 units of activity. Cells producing mutant forms of the hybrid proteins showed a wide range of overexpression. The two most extreme effects were seen by conversion of cysteine 38 to serine, which resulted in only a 1.6-fold increase in activity, and conversion of lysine 20 to glutamate, which resulted in a 15 -fold increase in activity, as compared to the normal protein. Mutations at GAL4 amino acids glutamate 8 , cysteine 21 , and tyrosine 40 caused approximately a threefold increase in $\beta$-galactosidase activity. Mutations at amino acids serine 6 , arginine 51 , and histidine 53 resulted in about a 6-fold increase in activity, and the mutation at amino acid lysine 43 resulted in a 13 -fold increase in the amount of $\beta$-galactosidase activity.

The amounts of wild-type and mutant GAL4- $\beta$-galactosidase proteins synthesized during a $30-\mathrm{min}$ period varied in proportion to their $\beta$-galactosidase activities. Cells producing normal and mutant forms of GAL4- $\beta$ galactosidase were radioactively labeled for $30 \mathrm{~min}$ and lysed immediately, and the resulting cell lysate was immunoprecipitated with anti- $\beta$-galactosidase. A radioactively labeled band of protein of the expected size (124

Table 1. Single amino acid changes in GAL4 that alter Gal- $\beta$ galactosidase nuclear localization and expression

\begin{tabular}{lccc}
\hline \multirow{2}{*}{$\begin{array}{l}\text { GAL4 amino } \\
\text { acid change }\end{array}$} & \multicolumn{2}{c}{$\beta$-Galactosidase units } & \multicolumn{2}{c}{$\begin{array}{c}\text { Complementation } \\
\text { of gal4 }\end{array}$} \\
\cline { 2 - 3 } None & 35 & 6 & + \\
Ser-6 to Phe & 207 & 11 & + \\
Glu-8 to Lys & 108 & 4 & + \\
Lys-20 to Glu & 515 & 13 & + \\
Cys-21 to Arg & 93 & 9 & - \\
Cys-38 to Ser & 59 & 1 & - \\
Tyr-40 to His & 130 & N.D. & + \\
Lys-43 to Glu & 461 & N.D. & + \\
Agr-51 to Gly & 221 & 4 & - \\
His-53 to Pro & 197 & N.D. & - \\
\hline
\end{tabular}

$\beta$-Galactosidase activity was determined for DB745 transformed with $\mathrm{P}_{(\mathrm{ADH})}-$ GAL4-lacZ, normal or mutant, on a multicopy plasmid or integrated into the chromosome (see Materials and methods). s.E. 15-23\%. Complementation of gal4 was determined in ML171 by the ability to induce GAL1-lacZ on Xgal indicator plates containing galactose. (N.D.) Not determined. 

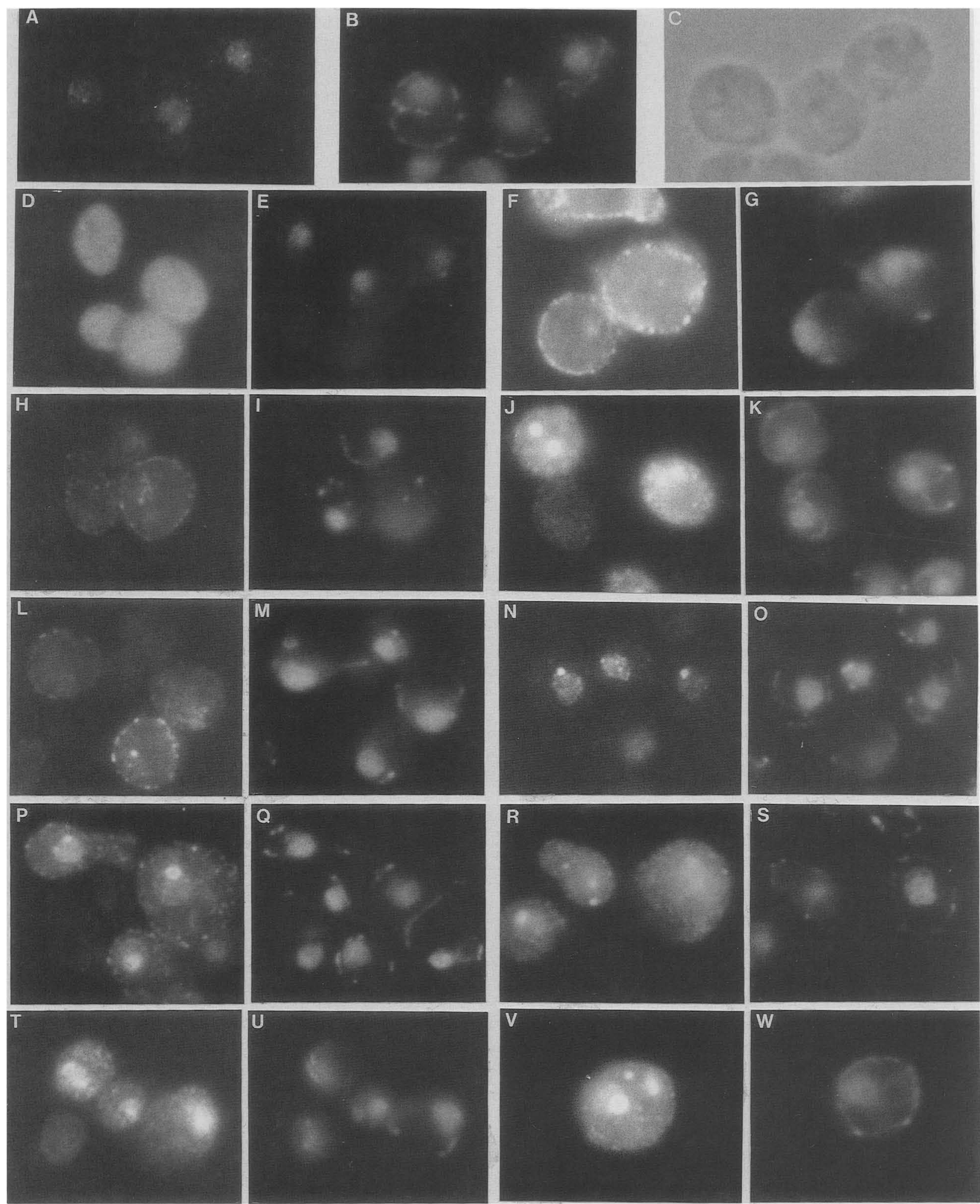

Figure 2. Immunofluorescence of cells producing normal and mutant forms of GAL4- $\beta$-galactosidase. Cells were prepared for immunofluorescence and treated with a mouse anti- $\beta$-galactosidase monoclonal antibody, followed by FITC-conjugated anti-mouse IgG, to localize the LacZ fusion proteins (Panels $A, D, F, H, J, L, N, P, R, T, V$ ), and DAPI to stain the cell DNA (Panels $B, E, G, I, K, M, O, Q, S, U, W$ ).

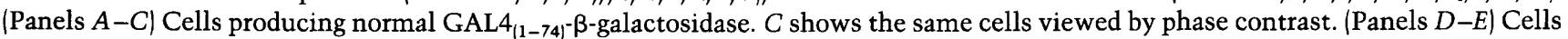
producing intact $\beta$-galactosidase. The remaining panels show immunofluorescence and DAPI stains of cells producing GAL4 $4_{(1-74)}-\beta$ galactosidase with the following amino acid changes; $(F, G)$ Ser 6 to Phe; $(H, I)$ Glu 8 to Lys; $(J, K)$ Lys 20 to Asp; $(L, M)$ Cys 21 to Arg; $(N, O)$ Cys 38 to Ser; $(P, Q)$ Tyr 40 to His; $(R, S)$ Lys 43 to Asp; $(T, U)$ His 53 to Pro; $(V, W)$ Arg 51 to Gly. Cells were prepared for immunofluorescence as described in Materials and methods. Exposure times for all immunofluorescence pictures were equal. 
$\mathrm{kD}$ ) was observed for cells producing normal GAL4- $\beta$ galactosidase (Fig. 3A, lane 2). Cells producing no LacZ fusion proteins showed no labeled protein in the corresponding region of the autoradiographed gel (Fig. 3A, lane 1). Cells producing mutant forms of GAL4- $\beta$-galactosidase all showed radioactively labeled proteins of the correct size (Fig. 3A, lanes 3-11). Moreover, there were no labeled proteins of lower molecular size, except for those nonspecifically and variably bound to the antibody-Staphylococcus aureus complex. Over the 30-min labeling period, cells producing proteins mutated at GAL4 amino acids lysine 20 (Fig. 3A, lane 5) and lysine 43 (Fig. 3A, lane 9) produced the highest amount of radioactively labeled protein, as compared to the wild-type protein (Fig. 3A, lane 2). Cells producing proteins with mutations at serine 6 (Fig. 3A, lane 3), tyrosine 40 (Fig.

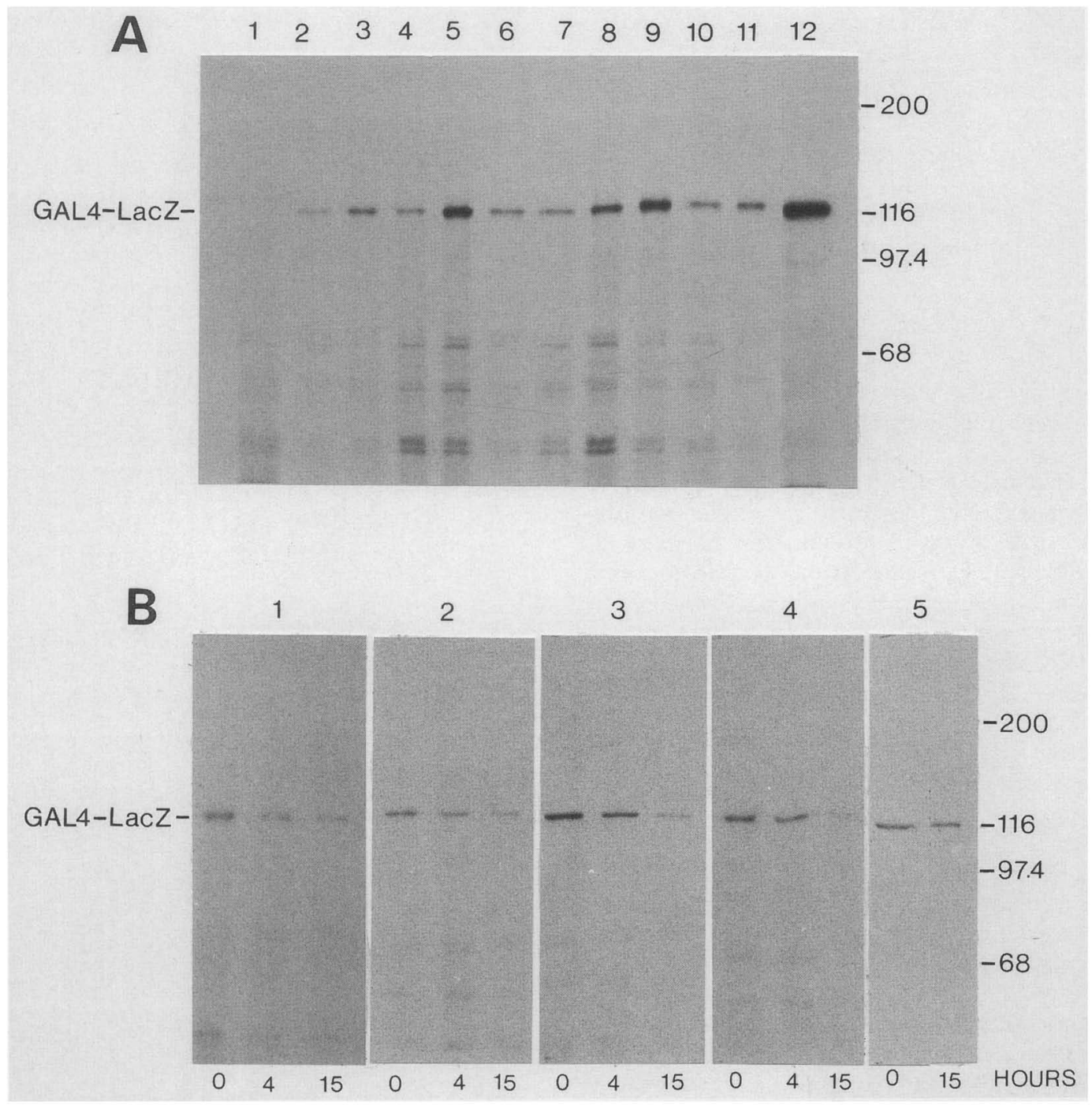

Figure 3. Mutations in GAL4 affect the production of GAL4- $\beta$-galactosidase. $(A)$ Relative synthesis rates of GAL4- $\beta$-galactosidase. Cells were pulse labeled with $\mathrm{SO}_{4}{ }^{2}$ - for $30 \mathrm{~min}$ and assayed immediately for GAL4- $\beta$-galactosidase by immunoprecipitation. Analyses were performed from cells transformed with YEp213, which does not encode lacZ (lane 1); cells transformed with PS1 18 (Fig. 1), which encodes normal GAL4 ${ }_{(1-74)}-$ LacZ (lane 2); or cells bearing gene fusions encoding amino acid changes at GAL4 amino acids Ser6 (lane 3), Glu 8 (lane 4), Lys 20 (lane 5), Cys 21 (lane 6), Cys 38 (lane 7), Tyr 40 (lane 8), Lys 43 (lane 9), and Arg 51 (lane 10), His 53 (lane 11) (For identification of the new amino acids, see Table 1). (Lane 12) Immunoprecipitation from cells producing intact $\beta$-galactosidase. Lower molecular weight bands are proteins that bind nonspecifically to the antibody-S. aureus complex and are precipitated to variable extents. $(B)$ Degradation rates of GAL4- $\beta$-galactosidase. The rate of degradation of normal and mutated GAL4 $4_{(1-74)}-\beta$-galactosidase was assayed by pulse labeling transformed cells for $30 \mathrm{~min}$ with ${ }^{35} \mathrm{SO}_{4}{ }^{2}$ and chasing with unlabeled $\mathrm{SO}_{4}{ }^{2}$, precisely as described in Materials and methods. Analyses were performed from cells transformed with PS118 (Panel 1) or cells bearing gene fusions encoding amino acid changes at GAL4 amino acids Ser 6 (panel 2), Lys 20 (panel 3), and Arg 51 (panel 4). Aliquots from each culture were removed and analyzed by immunoprecipitation with anti- $\beta$-galactosidase antibody at 0,4 , and $15 \mathrm{hr}$ after the addition of the unlabeled $\mathrm{SO}_{4}{ }^{2}$, as indicated at the bottom of the panels. Cells transformed with a plasmid producing intact $\beta$-galactosidase were analyzed at 0 and $15 \mathrm{hr}$ after the addition of unlabeled $\mathrm{SO}_{4}{ }^{2}$ (panel 5). The positions of protein standards (kD) are shown at the side of each gel. 
3A, lane 8), arginine 51 (Fig. 3A, lane 10), and histidine 53 (Fig. 3A, lane 11) showed slightly higher levels of labeled protein, as compared to cells producing proteins with mutations at glutamate 8 (Fig. 3A, lane 4), cysteine 21 (Fig. 3A, lane 6), and cysteine 38 (Fig. 3A, lane 7), and all produced more protein than cells producing the unmutated protein (Fig. 3A, lane 2).

\section{Overproduction is not due to increased protein stability or plasmid copy number}

The relative rate of degradation of several of the mutant proteins was not significantly different from the normal GAL4- $\beta$-galactosidase, and all the proteins appeared to be very stable. The rate of turnover of the normal and mutant proteins was measured by radioactively labeling cells that expressed the fusion proteins for $30 \mathrm{~min}$ and then chasing with unlabeled sulfate for up to $15 \mathrm{hr}$. In preliminary experiments, it was determined that the half-life of the fusion proteins was $>2 \mathrm{hr}$. Lysates were prepared from cells immediately and at 4 and $15 \mathrm{hr}$ after the addition of the chase. The amount of radioactively labeled GAL4- $\beta$-galactosidase present was determined by immunoprecipitation with anti- $\beta$-galactosidase antibody. At $4 \mathrm{hr}$ after the addition of the chase, approximately one half of the unmutated GAL4- $\beta$-galactosidase was still present, and by $15 \mathrm{hr}$ the protein was almost completely degraded (Fig. 3B, panel 1). A similar pattern of degradation was observed for proteins mutated at serine 6 (Fig. 3B, panel 2), lysine 20 (Fig. 3B, panel 3), and arginine 51 (Fig. 3B, panel 4); approximately one half of the labeled protein remained after $4 \mathrm{hr}$ of chase. Experiments with the other mutant proteins yielded similar results (data not shown). On the other hand, intact $\beta$-galactosidase was even more stable than any of the GAL4$\beta$-galactosidase hybrids; almost all of the labeled protein remained even after $15 \mathrm{hr}$ of chase (Fig. 3B, panel 5).

The differences between mutant and parental gene fusions in $\beta$-galactosidase levels lessened significantly when GAL4- $\beta$-galactosidase was produced from a single copy of the gene integrated into the chromosome at URA3. Cells containing a single copy of GAL4-lacZ produced 6 units of $\beta$-galactosidase activity (Table 1 ). Cells containing a single copy of gene fusions encoding changes at amino acids lysine 20 , serine 6 , and cysteine 21 caused a relative increase of 2-, 2-, and 1.5-fold, respectively, and the other mutants showed no detectable increase. In contrast, on multicopy plasmids, these same mutations caused increases of 15-, 6-, and 3-fold, respectively. Cells producing the protein with a mutation at cysteine 38 showed a significant decrease in the level of $\beta$-galactosidase activity. If the difference in activity observed when the fusion proteins were expressed from multicopy plasmids was due to decreased protease sensitivity of the mutant proteins, one would not expect this difference to be affected by the gene copy number. This is consistent with the finding that the half-lives of the parental and mutant fusion proteins are approximately the same (see above).

The overproduction of mutant GAL4- $\beta$-galactosidase cannot be accounted for by an increased plasmid copy number. The amount of wild-type plasmid (PS118) relative to the chromosomal URA3 DNA did not fluctuate by more than a factor of two when DNA was prepared from different transformants (Fig. 4, lanes 2-4). DNA prepared from cells bearing mutants that gave the highest level of overproduction (Fig. 4, lanes 4-9) showed less than a twofold difference in the amount of plasmid relative to the wild-type plasmid. However, the patterns of localization of the fusion proteins remained identical to that of proteins produced from multicopy plasmids (data not shown), except that the intensity of the immunofluorescence staining was reduced.

\section{Effect of mutations on GAL4 expression and activity}

All mutations were placed into intact GAL4. Lysates from yeast cells overproducing intact GAL4 from the $A D H 1$ promoter were examined by immunoblot analysis with anti-GAL4 antibody. As visualized in this way, GAL4 protein was modified to an apparently higher molecular weight form. Two bands specifically reacted with anti-GAL4 (Fig. 5, lane 5). The faster migrating band corresponded to a protein with an apparent molecular weight of 99,000 and comigrated with intact GAL4 extracted from a strain of $E$. coli that overproduces GAL4 (Fig. 5, lanes 2 and 15). An apparent molecular weight of 99,000 is in good agreement with the calculated molecular weight of 99,350 for GAL4 (Laughon and Gesteland 1982). The slower migrating band (Fig. 5, lane 5/ corre-

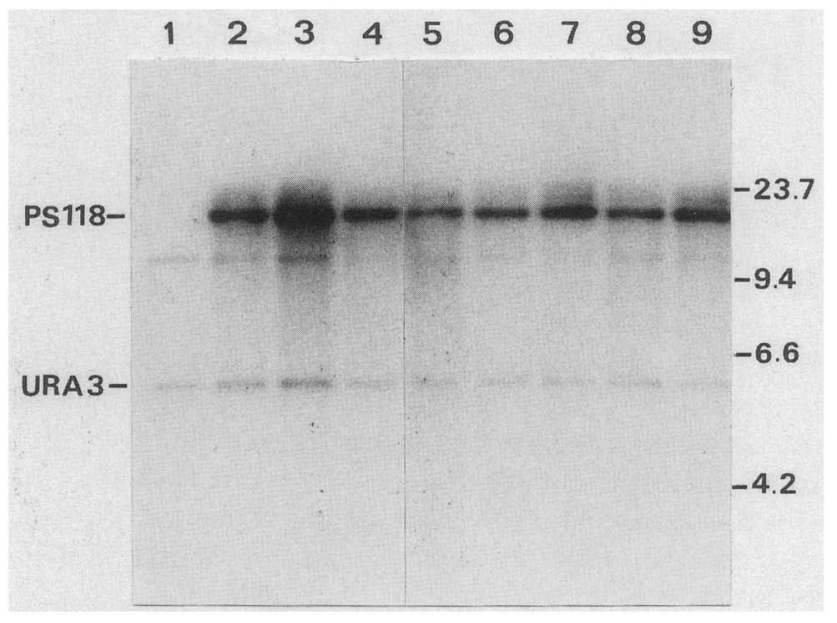

Figure 4. Determination of relative plasmid levels. The amount of plasmid in strains bearing wild-type or mutant forms of GAL4-lacZ on multicopy plasmids was determined by Southern blotting. Total cellular DNA from DB745 (lane 1), DB745 transformed with plasmids bearing wild-type GAL4lacZ (lanes 2-4), or DB745 transformed with plasmids bearing mutations at GAL4 Lys 43 (lane 5), His 53 (lane 6), Arg 51 (lane 7), Ser 6 (lane 8), or Lys 20 (lane 9) was digested with BamHI and electrophoresed on a $0.6 \%$ agarose gel. Lanes 2 and 4 contain approximately equal amounts of DNA prepared from two different PS1 18 transformants. Lane 3 contains twice as much of the sample as lane 4 . The blot was probed as described in Materials and methods. The positions of DNA standards $(\mathrm{kb})$ are shown at the side of the gel. 


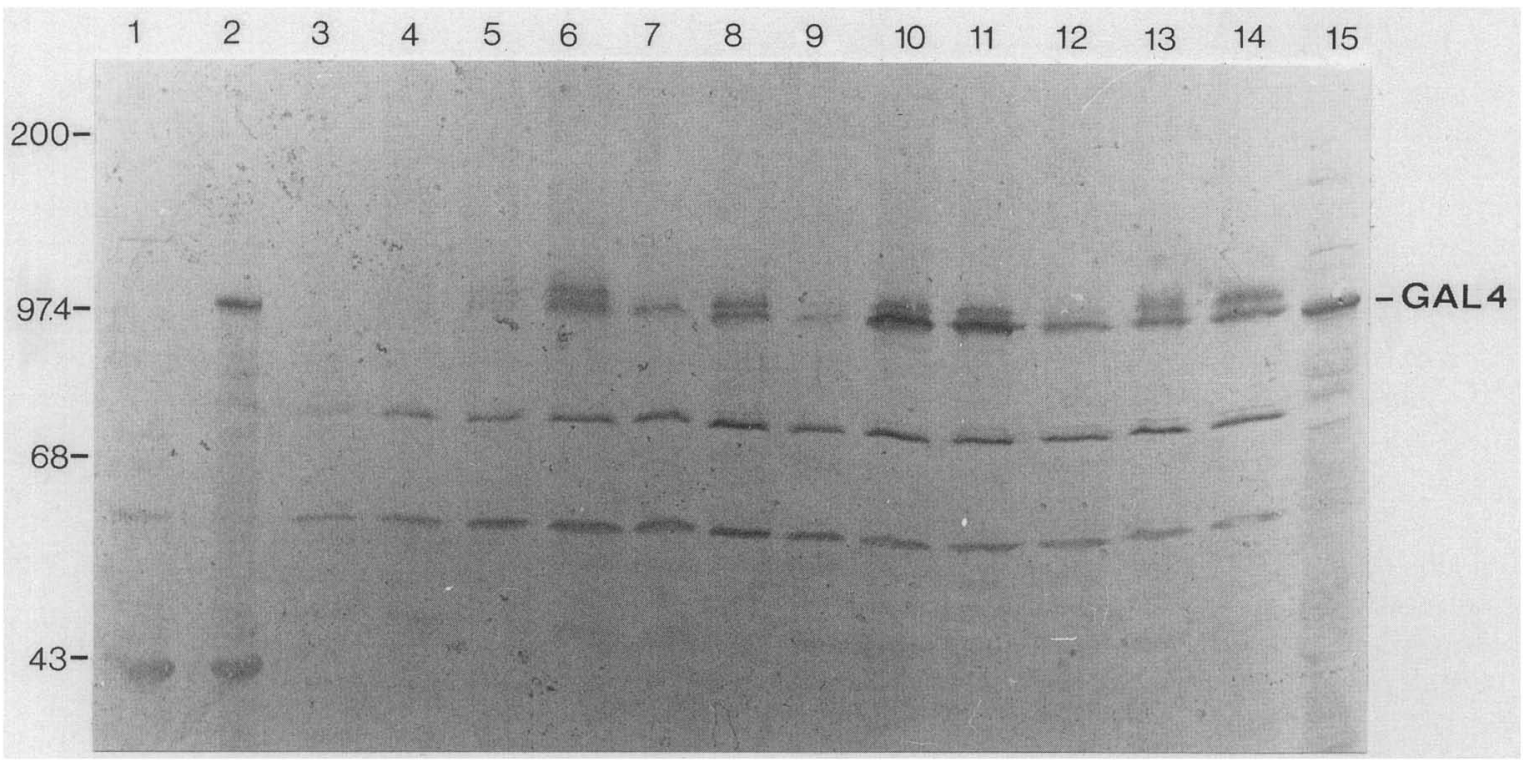

Figure 5. Mutations affect the level of intact GAL4 protein. Cell extracts from DB745 containing plasmids encoding normal and mutated GAL4 and E. coli JM107, without or with pLK76-7, were subjected to SDS-PAGE (7\%) gel. Proteins were transferred to nitrocellulose and probed with rabbit anti-GAL4 antibody and goat anti-rabbit IgG conjugated with horseradish peroxidase. (Lane 1) JM107; (lanes 2 and 15) JM107/pLK76-7; (lane 3) DB745/YEp213 (no GAL4); (lane 4) DB745 transformed with a plasmid expressing GAL4 from its own promoter; (lane 5) DB745 transformed with a plasmid causing the overproduction of GAL4 from the ADH promoter. The remaining lanes contain lysates prepared from DB745 transformed with plasmids that cause the overproduction from the $\mathrm{ADH}$ promoter of GAL4 with amino acid changes at Cys 38 (lane 6), Arg 51 (lane 7), Ser 6 (lane 8), Glu 8 (lane 9), Lys 20 (lane 10), Lys 43 (lane 11 ), His 53 (lane 12), Cys 21 (lane 13), and Tyr 40 (lane 14). The positions of protein standards (kD) are shown at the side of the gel. Proteins corresponding to molecular weights of 80,000 and 61,000 reacted nonspecifically with the anti-GAL4 antiserum by two criteria; both proteins were still observed when a strain deleted for GAL4 was similarly examined, and they were not observed when affinity-purified anti-GAL4 antibody was used to probe a similar blot.

sponded to a protein of apparent molecular weight of about 106,000 . Neither protein was detectable in extracts prepared from yeast cells not overproducing GAL4 (Fig. 5, lane 3), even though the strain is GAL4. Both forms of GAL4 were barely detectable from cells transformed with a wild-type copy of GAL4 on a multicopy plasmid (Fig. 5, lane 4).

Mutations in GAL4 cause the overproduction of both forms of GAL4, with two exceptions. Lysates from cells producing mutant forms of GAL4 were also examined by immunoblot with anti-GAL4 antibody (Fig. 5). Two bands corresponding to molecular weights of 99,000 and 106,000 appeared in lysates prepared from cells producing GAL4 mutated at amino acids cysteine 38 (lane 6), serine 6 (lane 8 ), lysine 20 (lane 10), lysine 43 (lane 11), cysteine 21 (lane 13), and tyrosine 40 (lane 14). In this particular experiment, cells producing GAL4 mutated at glutamate 8 revealed a marginally detectable amount of the slower migrating form of GAL4 (lane 9). But in other experiments, almost equal amounts of both forms were detected for GAL4 mutated at glutamate 8 . On the other hand, extracts prepared from cells producing GAL4 with amino acid changes at arginine 51 (lane 7) and histidine 53 (lane 12) reproducibly showed very little of the slower migrating form of GAL4. The amount of GAL4 detected by immunoblots was greater for all the mutants, as compared to the amount of wildtype GAL4 (cf. lanes 6-14 to lane 5). GAL4 mutated at amino acids lysine 20 (lane 10), lysine 43 (lane 11), cysteine 21 (lane 13), and tyrosine 40 (lane 14) showed the most overproduction, consistent with the effect of these mutations on GAL4- $\beta$-galactosidase expression.

GAL4 mutated at amino acids cysteine 21 , cysteine 38 , arginine 51 , and histidine 53 no longer retained GAL4 activity. GAL4 activity was determined by testing the ability of the overproduced mutant proteins to activate a GAL1-lacZ gene fusion in a gal4 strain (Table 1). Mutations at serine 6, glutamate 8 , lysine 20, tyrosine 40 , and lysine 43 retained GAL4 function, whereas mutations at cysteine 21 , cysteine 38 , arginine 51 , and histidine 53 lacked GAL4 function by this criteria.

\section{Some mutations affect localization of intact GAL4 protein}

Intact GAL4 protein is localized exclusively to the cell nucleus. Cells producing intact GAL4 protein from the $A D H 1$ promoter on a multicopy plasmid were examined by immunofluorescence, using an anti-GAL4 antibody (Fig. 6A-C). About $25 \%$ of the cells showed faint nuclear-associated immunofluorescence. Cells not overproducing GAL4 did not stain with the antibody (Fig. $6 \mathrm{P}$ ), even though the strain was $G A L 4$ and, thus, produced a small amount of GAL4 protein.

Mutations in the first 74 GAL4 amino acids affected normally nuclear localization of intact GAL4 to varying 
Nuclear protein localization
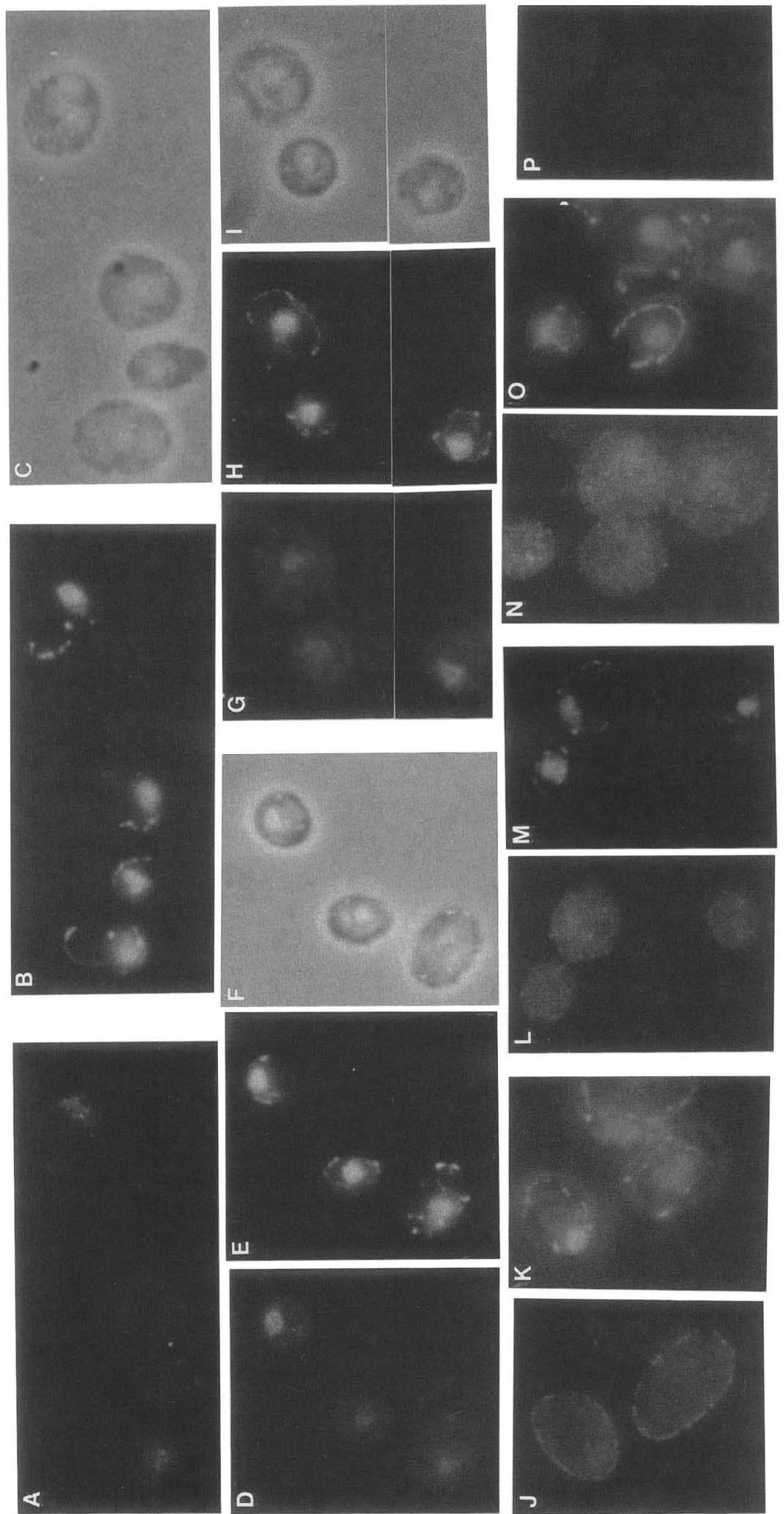

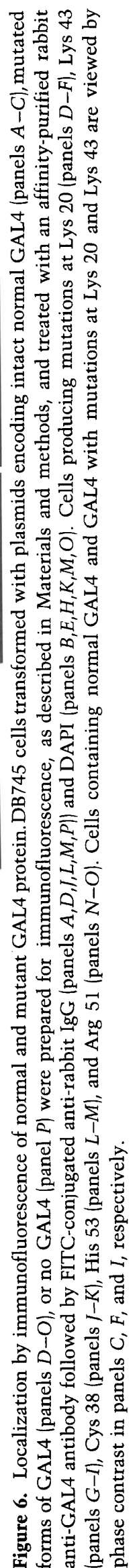


degrees. GAL4 mutated at lysine 20 appeared still mainly nuclear localized (Fig. 6D-F), although the intensity of immunofluorescence was increased, as compared to the staining seen with normal GAL4 (cf. Fig. 6D and A). GAL4 mutated at lysine 43 showed mainly nuclear-associated immunofluorescence with some increase in cytoplasmic staining, as compared to cells producing normal GAL4. Cells producing intact GAL4 mutated at cysteine 38 (Fig. 6J-K), histidine 53 (Fig. 6L-M), and arginine 51 (Fig. $6 \mathrm{~N}, \mathrm{O}$ ) showed an even greater increase in the amount of cytoplasmic immunofluorescence. GAL4 mutated at cysteine 21 also showed a faint increase in nonnuclear staining, but the signal was too faint to be adequately reproduced photographically. GAL4 mutated at serine 6 , glutamate 8 , and tyrosine 40 could not be seen at all by immunofluorescence.

\section{Discussion}

We have identified nine point mutations within the first 74 codons of GAL4 that result in single amino acid changes. Changes between GAL4 amino acids 6 and 53 affect both the degree of nuclear localization and the level of production of a GAL4- $\beta$-galactosidase fusion protein.

Within intact GAL4, these mutations have similar effects. Mutant GAL4 proteins are overproduced, as are mutant GAL4- $\beta$-galactosidase proteins. Some mutant GAL4 proteins are also mislocalized, although to a lesser extent than the corresponding GAL4- $\beta$-galactosidase protein. The presence of GAL4 amino acids $75-881$ may assist amino acids $1-74$ in assuming a conformation required for proper localization.

The nine amino acid changes that cause nonnuclear GAL4- $\beta$-galactosidase to accumulate are distributed throughout GAL4 amino acids 1-74. Although all the changes are nonconservative, there is no consistent pattern of replacement with respect to charge or hydrophobicity. This suggests that the entire $1-74$ region is somehow important for nuclear localization. In contrast, other nuclear targeting sequences are very short; e.g., the SV40 sequence PKKKRKV (Kalderon et al. 1984) is sufficient for nuclear localization of $\beta$-galactosidase in yeast (I. Sadler and P.A. Silver, unpubl.).

This paradox might be resolved in several ways. The first 74 GAL4 amino acids could contain several shorter nuclear localization sequences, as has been proposed for MAT $\alpha 2$ (Hall 1986; Silver and Hall 1988) and polyoma large $\mathrm{T}$ antigen (Richardson et al. 1986). Mutations in one might reduce nuclear localization only partially. Alternatively, they could be altering the folding of the first 74 GAL4 amino acids and, hence, obscure a shorter nuclear targeting sequence. Protein context has been shown to affect the function of nuclear localization signals (Roberts et al. 1987). Another possibility is that misfolding of the protein could result in aberrant binding to other cellular components, as is the case of mutant forms of influenza hemagglutinin that fail to be transported out of the endoplasmic reticulum (Gething et al. 1986). Finally, the entire amino-terminal 74 amino acids may be recognized for nuclear localization, and a perturbation anywhere in its sequence could disrupt its ability to promote nuclear transport.

Overproduction of GAL4- $\beta$-galactosidase protein is unlikely to directly cause improper localization. Mutant proteins expressed from a single gene copy are also mislocalized. Also, one mutation, lysine 20 to glutamate, causes nonnuclear GAL4- $\beta$-galactosidase to accumulate. However, intact GAL4 bearing this mutation is almost completely nuclear localized but still overproduced. More likely, lack of complete localization is due to failure of the mutant proteins to interact properly with the localization apparatus.

The lysine 20 to glutamate mutation has a variable effect on protein localization, depending on the protein context. Similarly, the mutation cysteine 38 to serine has only a small effect on nuclear localization and production of GAL4- $\beta$-galactosidase. On the other hand, intact GAL4 bearing this mutation is overproduced and found in both the cytoplasm and the nucleus. These apparent inconsistencies further reveal the importance of overall protein context for the function of nuclear localization sequences (Roberts et al. 1987).

The mutations were isolated because they cause an increase in $\beta$-galactosidase activity from a GAL4-lacZ fusion carried on a multicopy plasmid, as assayed on $\mathrm{X}$-gal indicator plates. In principle, such an increase could result from an increase in plasmid copy number, transcription, mRNA stability, translation, protein stability, or enzyme activity. However, the plasmid copy number (Fig. 4) and protein stability (Fig. 3B) in the mutants is the same as that of the parental construction, and the mutants show an increase in the level of fusion protein synthesized (Fig. 3A), rather than an alteration in specific activity. Therefore, the difference in levels of $\beta$ galactosidase activity between the mutants and their parent appears to result from transcription, mRNA stability, or translation, i.e., in some aspect of the production of the protein. All fusions are expressed from the same promoter, making differences in transcription levels unlikely. [Preliminary experiments indicate only slight differences in steady-state RNA levels, which are not, by themselves, sufficient to account for differences in protein levels (P. Silver, unpubl.)]. A limited cellular factor may be necessary for translation of the normal GAL4 protein, hence, limiting the level to which it can be overproduced. The mutations identified here might alter the interaction of the GAL4 amino-terminus with this factor and allow more efficient translation.

In other cases, localization of proteins to the nucleus is correlated with a decrease in production of the localized protein relative to similar, nonlocalized controls. Hall et al. (1984) showed that yeast strains with nuclearlocalized MAT $\alpha 2-\beta$-galactosidase fusion proteins exhibited less $\beta$-galactosidase activity than strains with nonlocalized fusions. Similarly, Moreland et al. (1985) examined fusions between $\beta$-galactosidase and yeast ribosomal protein $\mathrm{L} 3$, which is localized to the nucleus prior to assembly into ribosomes. Fusions that contain a complete nuclear targeting sequence were synthesized 
at lower levels than corresponding proteins lacking the targeting sequence. We suggest that the underlying control mechanism in these cases, as well as for GAL4, may be the same.

By overproducing GAL4 from the strong $A D H 1$ promoter, we have identified two forms of GAL4 protein. Two of the GAL4-linked mutations, at arginine 51 and histidine 53, appear to block the production of the higher molecular weight form of GAL4. We do not know how this new form of GAL4 is modified. One possibility is that the active form of GAL4 is modified by phosphorylation by the protein kinase encoded by SNF1 (Celenza and Carlson 1986). Genes regulated by GAL4 are subject to glucose repression (for review, see Johnston 1987a). snf1 cells are also gal $^{-}$, suggesting that SNF1 may exert its effect via GAL4.

The mutations we have identified in the GAL4 amino-terminus that alter nuclear localization have varying effects on the ability of GAL4 to act as a positive regulator. The GAL4 DNA-binding domain is also contained in the first 74 amino acids and contains six cysteines that may be involved in chelating a metal such as zinc (Miller et al. 1985; Johnston 1987). We have now identified two mutations, one at cysteine 21 and the other at cysteine 38 that eliminate the ability of GAL4 to complement a gal4 strain. Because the GAL4 DNAbinding and nuclear localization determinants overlap, it would not be surprising if some mutations disrupt both functions.

\section{Materials and methods}

\section{Strains and plasmids}

S. cerevisiae strains used were DB745 lade1-100 leu2-3 leu2-112 ura3-52), and ML171 (leu2-3 leu2-112 ade1-100 gal4 ura3 :: GAL1-lacZ, provided by M. Lamphier). E. coli strains MM294 (end hsdR thi pro) and JM107 [ $\Delta$ (lac pro) thi strA supE endA F'proAB lacIa Z $\Delta M 15$ ] were used for construction and maintenance of plasmids. NK5480 larg leu his thr trp mutD, provided by $\mathrm{N}$. Kleckner) was used for plasmid mutagenesis. Plasmid pPS118 containing $P_{A D H}-$ GAL4(1-74)-lacZ in YEp213 has been described (Silver et al. 1984) and is shown in Figure 1. Plasmid pLK76-7 causes the overproduction of GAL4 from the tac promoter in E. coli (Keegan et al. 1986).

\section{Microbial techniques}

Minimal selective growth medium with $2 \%$ glucose was as described in Sherman et al. (1983). Wickerham's minimal medium (Wickerham 1946), with sulfate salts replaced by chloride salts with $2 \%$ glucose as a carbon source, was used for ${ }^{35} \mathrm{SO}_{4}{ }^{2-}$ labeling. Yeast transformation was performed by the lithium acetate method of Ito et al. (1983), using $50 \mu \mathrm{g}$ of salmon sperm DNA (Sigma) per transformation. Media for growing $E$. coli are as described (Miller 1972).

\section{$\beta$-Galactosidase assays}

Cells were grown to between $\mathrm{OD}_{600} 0.5$ and 1.0 , and $0.1 \mathrm{ml}$ was assayed, as described previously (Guarente and Ptashne 1981). Each reported value is the average of at least three individual assays conducted on independently isolated yeast colonies. XG plates were used, as described previously (Guarente and Ptashne 1981).

\section{Isolation and characterization of GAL4-linked point mutations}

NK5480 was grown in TB media and transformed with pPS118 DNA. Transformants were selected on LB plates containing ampicillin. Plasmid DNA was purified from 10 individual transformants and introduced into DB745 (Ito et al. 1983). Yeast transformants were selected on leucine dropout plates containing $2 \%$ glucose. The resulting transformants (4000) were then replica plated to leucine dropout plates with $2 \%$ glucose and X-gal. About $1 \%$ of the transformants had no $\beta$-galactosidase activity (white on X-gal plates), and about $1 \%$ showed increased $\beta$-galactosidase activity on XG plates when compared to cells bearing unmutagenized pPS118.

Plasmid DNA was isolated from the dark blue mutant colonies and used to retransform several different yeast strains to demonstrate linkage of the mutant phenotypes to the plasmids. To demonstrate that the mutations were in the GAL4 region of the plasmid, the HindIII-Xhol fragment (Fig. 1) was excised from the mutant plasmid and ligated to an unmutagenized backbone plasmid containing the $A D H 1$ promoter and $l a c Z$ in YEp213. Ten mutations were demonstrated to be GAL4-linked and were sequenced by cloning the HindIII-XhoI fragment into M13, which was subjected to dideoxy sequencing (Sanger et al. 1977). Two different mutant plasmids contained the same mutation at the codon corresponding to tyrosine 40 .

GAL4-linked mutations were reconstructed into the intact GAL4 by placing the GAL4 HindIII-XhoI fragment into a plasmid that contained the intact GAL4 gene expressed from the $A D H 1$ promoter (Silver et al. 1984). Chromosomally integrated forms of $G A L 4-1 a c Z$ were prepared by inserting the BamHI-SalI fragment (Fig. 1) into the integrating plasmid YIp5 (Botstein and Davis 1982). The resulting plasmid (PS106) was digested with ApaI to target integration to the URA3 locus.

\section{Immunofluorescence}

Cells were grown in minimal selective media with $2 \%$ glucose at $30^{\circ} \mathrm{C}$ and prepared for indirect immunofluorescence as described previously (Silver et al. 1984), with the following modifications. Cells were fixed by adding formaldehyde to a final concentration of $3.5 \%$ (vol/vol) directly to the growing culture and incubated with gentle shaking for $90 \mathrm{~min}$ at $30^{\circ} \mathrm{C}$. After washing and digestion with zymolyase 60,000 (Kirin), the cells were placed on a polylysine coated multiwell slide (Flow Laboratories) and immersed in cold methanol and acetone. Antibodies were diluted in $1 \mathrm{mg} / \mathrm{ml}$ bovine serum albumin (BSA) (Sigma) in phosphate-buffered saline (PBS) (0.04 $\mathrm{M} \mathrm{K}_{2} \mathrm{HPO}_{4}, 0.01$ $\mathrm{M} \mathrm{KH}_{2} \mathrm{PO}_{4}, 0.15 \mathrm{M} \mathrm{NaCl}$ ). To visualize GAL4- $\beta$-galactosidase (Fig. 2), a mouse monoclonal anti- $\beta$-galactosidase antibody (from T. Mason) at a dilution of 1:500 was used, followed by FITC-conjugated goat anti-mouse IgG (Boehringer Mannheim) at $1: 500$ dilution. To visualize intact GAL4 (Fig. 4), affinitypurified rabbit anti-GAL4 antibody (from C. Debouck) was used at $1: 100$ dilution, followed by FITC-conjugated goat antirabbit IgG (Miles) at $1: 200$. Anti-GAL4 antibody was affinity purified by passing it over a Sepharose column to which a peptide containing GAL4 amino acids 1-147 (from M. Hollis and M. Ptashne) had been coupled. Cells were viewed at $1000 \times$ magnification with either a Zeiss Photo III microscope or Zeiss Axioskop, both equipped for fluorescence. Exposure times for immunofluorescence were $30 \mathrm{sec}$ in all cases. 


\section{Pulse-labeling experiments}

Cells were grown at $30^{\circ} \mathrm{C}$ to a cell density of $1 \times 10^{7}$ cells $/ \mathrm{ml}$ in $5 \mathrm{ml}$ of media (Wickerham 1946), supplemented with $0.1 \mathrm{mM}$ ammonium sulfate, collected by centrifugation $(2500 \mathrm{~g}$ for 5 $\mathrm{min}$ ), and resuspended in $1 \mathrm{ml}$ prewarmed sulfate-free media with $0.1 \mathrm{mCi} \mathrm{Na}_{2}{ }^{35} \mathrm{SO}_{4}(574 \mathrm{mCi} / \mathrm{mmole}$, DuPont NEN). Following incubation for $30 \mathrm{~min}$ at $30^{\circ} \mathrm{C}$, ammonium sulfate $(5$ $\mathrm{mM}$ final concentration) and cycloheximide (1 $\mathrm{mM}$ final concentration) were added. At the indicated time points, cells $(0.3$ ml) were immediately chilled, collected by centrifugation $(5000 \mathrm{~g}, 2 \mathrm{~min})$, resuspended in $0.5 \mathrm{ml}$ cold buffer A $[150 \mathrm{~mm}$ $\mathrm{NaCl} / 50 \mathrm{~mm}$ Tris-Cl (pH 7.5)/5 mM EDTA/1\% (vol/vol) Triton $\mathrm{X}-100 / 1 \mu \mathrm{g} / \mathrm{ml}$ leupeptin and pepstatin] and glass beads to one quarter the final volume, and lysed by three 30 -sec agitations on a VWR vortex mixer. The lysate was centrifuged $(14,000 \mathrm{~g}, 3$ $\mathrm{min})$, and the resulting supernatant was analyzed as described below.

\section{Immunoprecipitation}

Immunoprecipitation of GAL4- $\beta$-galactosidase was achieved by the addition of $50 \mu \mathrm{l}$ of the mouse monoclonal anti- $\beta$-galactosidase to $0.3 \mathrm{ml}$ of cell lysate for $1 \mathrm{hr}$ at $4^{\circ} \mathrm{C}$, followed by $50 \mu \mathrm{l}$ of a $10 \%$ (wt/vol) suspension of formalin-fixed, SDS-washed $S$. aureus (from $M$. Resh) for an additional $1 \mathrm{hr}$ at $4^{\circ} \mathrm{C}$. The $S$. aureus were then sedimented $\left(14,000 \mathrm{~g}, 3 \mathrm{~min}, 4^{\circ} \mathrm{C}\right)$, washed twice with buffer A $(0.5 \mathrm{ml})$, and washed once with buffer A containing $0.1 \%$ SDS. The final cell pellet was resuspended in $50 \mu \mathrm{l}$ sample buffer (Laemmli 1970), boiled for $5 \mathrm{~min}$ and sedimented for $5 \mathrm{~min}$ at $14,000 \mathrm{~g}$, and the supernatant was analyzed by SDS-gel electrophoresis (Laemmli 1970) and fluorography (Chamberlin 1979).

\section{Plasmid levels}

Total DNA was isolated from plasmid bearing cells $12 \times 10^{8}$ cells $/ \mathrm{ml}$ ) grown in selective media (Sherman et al. 1983), separated by electrophoresis in a $0.6 \%$ agarose gel and transferred to nitocellulose by the method of Southern (1975). The plasmid pPS106 that contains $\mathrm{P}_{\mathrm{ADH}}$ GAL4-lacZ from PS1 18 cloned into YIp5 was used as the nick-translated probe.

\section{Immunoblots}

Immunoblotting was used to quantify the amount of intact GAL4 protein. Cells ( $5 \mathrm{ml}$ of $1 \times 10^{7}$ cells $\left./ \mathrm{ml}\right)$ were collected by centrifugation $(2600 \mathrm{~g}, 5 \mathrm{~min})$, resuspended in $1 \mathrm{ml}$ of $0.25 \mathrm{M}$ $\mathrm{NaOH} / 1 \% \beta$-mercaptoethanol, and incubated for $10 \mathrm{~min}$ on ice. Then, $0.16 \mathrm{ml}$ of trichloroacetic acid $(50 \%)$ was added, and the cells were incubated for $10 \mathrm{~min}$ on ice and collected by centrifugation $(14000 \mathrm{~g}, 10 \mathrm{~min})$. The pellet was washed with cold acetone $(1 \mathrm{ml})$, allowed to air-dry, resuspended in $0.2 \mathrm{ml}$ sample buffer, boiled for $5 \mathrm{~min}$, and electrophoresed on a 7\% SDSpolyacrylamide gel (Laemmli 1970). Equal amounts of protein were loaded for each lysate, as determined by Coomassie staining of an identical gel run in parallel. Following electrophoresis, the proteins were transferred to nitrocellulose with a Polyblot Electroblotter (ABN). The nitrocellulose blot was blocked and incubated with antibodies, as described previously (Silver et al. 1984). Rabbit serum containing anti-GAL4 antibody (from S. Chapman) and goat anti-rabbit IgG conjugated with horseradish peroxidase (BioRad) were each used at $1: 200$ dilution.

E. coli extracts were prepared from JM107 transformed with pLK76-7. Cells were grown in LB containing ampicillin 120 $\mu \mathrm{g} / \mathrm{ml}$ ). At $\mathrm{OD}_{600}$ of 1 , IPTG was added (final concentration 5 $\mathrm{mM}$ ). Cells were then incubated for $2 \mathrm{hr}$ at $37^{\circ} \mathrm{C}$, collected by centrifugation $(14,000 \mathrm{~g}, 5 \mathrm{~min})$, and lysed by resuspension in sample buffer and boiling for $5 \mathrm{~min}$.

\section{Acknowledgments}

We especially thank M. Ptashne, in whose lab the initial stages of this work were done, and C. Romano and W. Raymond, who helped with the original mutant isolation. We thank $M$. Samuels for reading the manuscript, J. Way for many helpful discussions, and S. Chapman, S. Varnum, and X. Yang for technical assistance. This work was supported by National Institutes of Health grant GM36373-01. I. Sadler is supported by a NATO/Deutschen Akademischer Austauschdienst postdoctoral fellowship.

\section{References}

Botstein, D. and R.W. Davis. 1982. Principles and practice of recombinant DNA research with yeast. In The Molecular biology of the yeast Saccharomyces cerevisiae. Metabolism and gene expression (ed. J.N. Strathern, E.W. Jones, and J.R. Broach), pp. 607-636. Cold Spring Harbor Laboratory, Cold Spring Harbor, New York.

Celenza, J.L. and M. Carlson. 1986. A yeast gene that is essential for release from glucose repression encodes a protein kinase. Science 233: 1123-1127.

Chamberlin, J.P. 1979. Fluorographic detection of radioactivity in polyacrylamide gels with the water-soluble fluor, sodium salicylate. Anal. Biochem. 98: 132-135.

Douglas, H. and D. Hawthorne. 1972. Uninducible mutants in the gal i locus of Saccharomyces cerevisiae. I. Bacteriol. 109: 1139-1143.

Gething, M.-J., K. McCammon, and J. Sambrook. 1986. Expression of wild-type and mutant forms of influenza hemaglutinin: The role of folding in intracellular transport. Cell 46: 939-950.

Giniger, E., S.M. Varnum, and M. Ptashne. 1985. Specific DNA binding of GAL4, a positive regulatory protein of yeast. Cell 40: $767-774$.

Goldfarb, D.S., J. Gariepy, G. Schoolnik, and R.D. Kornberg. 1986. Synthetic peptides as nuclear location signals. Nature 322: $641-644$.

Guarente, L. and M. Ptashne. 1981. Fusion of Eschericia coli lacZ to the cytochrome c gene of Saccharomyces cerevisiae. Proc. Natl. Acad. Sci. 78: 2199-2203.

Hall, M.N. 1986. Nuclear protein localization signals in yeast. In Yeast cell biology. (ed. J. Hicks), pp. 421-425. Alan R. Liss, New York.

Hall, M.N., L. Hereford, and I. Herskowitz. 1984. Targeting of E. coli beta-galactosidase to the nucleus in yeast. Cell 36: 1057-1065.

Ito, H., Y. Fukado, K. Murata, and A. Kimura. 1983. Transformation of intact yeast cells with alkali cations. $J$. Bacteriol. 153: $163-168$.

Johnston, M. 1987a. A model fungal gene regulatory mechanism: The GAL genes of Saccharomyces cerevisiae. Microbiol. Rev. 51: 458-476.

. 1987b. Genetic evidence that zinc is an essential cofactor in the DNA binding domain of GAL4 protein. Nature 328: 353-355.

Kalderon, D., B.L. Roberts, W.D. Richardson, and A.E. Smith. 1984. A short amino acid sequence able to specify nuclear location. Cell 39: 499-509.

Keegan, L.P., G. Gill, and M. Ptashne. 1986. Separation of DNA 
binding from the transcription-activating function of a eukaryotic regulatory protein. Science 231: 699-704.

Laemmli, U.K. 1970. Cleavage of structural proteins during the assembly of the head bacteriophage T4. Nature 227: 680685.

Lanford, R.E., P. Kanda, and R.C. Kennedy. 1986. Induction of nuclear transport with a synthetic peptide homologous to the SV40 T antigen transport signal. Cell 46: 575-582.

Laughon, A. and R.F. Gesteland. 1982. Primary structure of the Saccharomyces cerevisiae GAL4 gene. Mol. Cell. Biol. 4: $260-267$.

Miller, J. 1972. Experiments in molecular genetics. Cold Spring Harbor Laboratory, Cold Spring Harbor, New York.

Miller, J., A.D. McLachlan, and A. Klug. 1985. Repetitive zincbinding domains in the protein transcription factor IIIA from Xenopus oocytes. EMBO J. 4: 1609-1614.

Moreland, R.B., H.G. Nam, L.M. Hereford, and H.M. Fried. 1985. Identification of a nuclear localization signal of a yeast ribosomal protein. Proc. Natl. Acad. Sci. 82: 6561-6565.

Moreland, R.B., G.L. Langevin, R.H. Singer, R.L. Garcea, and L.M. Hereford. 1987. Amino acid sequences that determine the nuclear localization of yeast histone H2B. Mol. Cell. Biol. 7: 4048-4057.

Paucha, E., D. Kalderon, W.D. Richardson, R.W. Harvey, and A.E. Smith. 1985. The abnormal location of cytoplasmic SV40 large $T$ is not caused by failure to bind to DNA or p53. EMBO J. 4: 3235-3240.

Richardson, W.D., B.L. Roberts, and A.E. Smith. 1986. Nuclear location signals in polyoma virus large-T. Cell 44: 77-85.

Roberts, B.L., W.D. Richardson, and A.E. Smith. 1987. The effect of protein context on nuclear location signal function. Cell 50: 465-475.

St. John, T. and R. Davis. 1981. The organization and transcription of the galactose gene cluster of Saccharomyces. J. Mol. Biol. 152: 285-315.

Sanger, F., S. Nicklen, and A.R. Coulson. 1977. DNA sequencing with chain terminating inhibitors. Proc. Natl. Acad. Sci. 74: 5463-5467.

Sherman, F., G. Fink, and C. Lawrence. 1983. Methods in yeast genetics, revised ed. Cold Spring Harbor Laboratory, Cold Spring Harbor, New York.

Silver, P.A. and M.N. Hall. 1988. Transport of proteins into the nucleus. In Protein transfer and organelle biogenesis, (ed. R.C. Das and P.W Robbins). pp. 747-769. Academic Press, New York.

Silver, P., R. Brent, and M. Ptashne. 1986. DNA binding is not sufficient for nuclear localization of regulatory proteins in Saccharomyces cerevisiae. Mol. Cell. Biol. 6: 4763-4766.

Silver, P., L. Keegan, and M. Ptashne. 1984. Amino terminus of the yeast GAL4 gene product is sufficient for nuclear localization. Proc. Natl. Acad. Sci. 81: 5951-5955.

Southern, E. 1975. Detection of specific sequences among DNA fragments separated by gel electrophoresis. I. Mol. Biol. 98: $503-517$.

Wickerham, L.J. 1946. A critical evaluation of the nitrogen assimilation tests commonly used in the classification of yeasts. J. Bacteriol. 52: 293-301. 


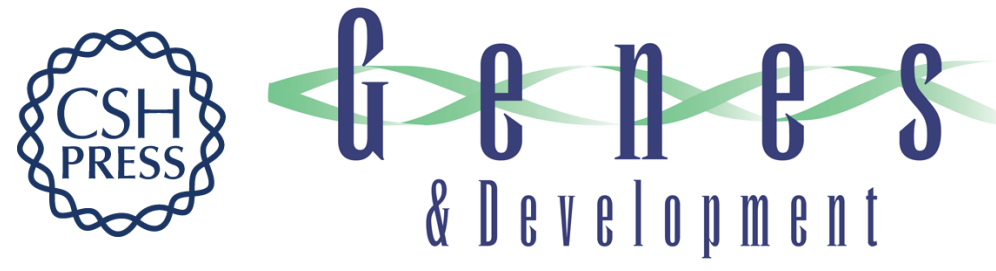

\section{Mutations that alter both localization and production of a yeast nuclear protein.}

P A Silver, A Chiang and I Sadler

Genes Dev. 1988, 2:

Access the most recent version at doi:10.1101/gad.2.6.707

References This article cites 28 articles, 11 of which can be accessed free at:

http://genesdev.cshlp.org/content/2/6/707.full.html\#ref-list-1

License

Email Alerting

Service

Receive free email alerts when new articles cite this article - sign up in the box at the top right corner of the article or click here.

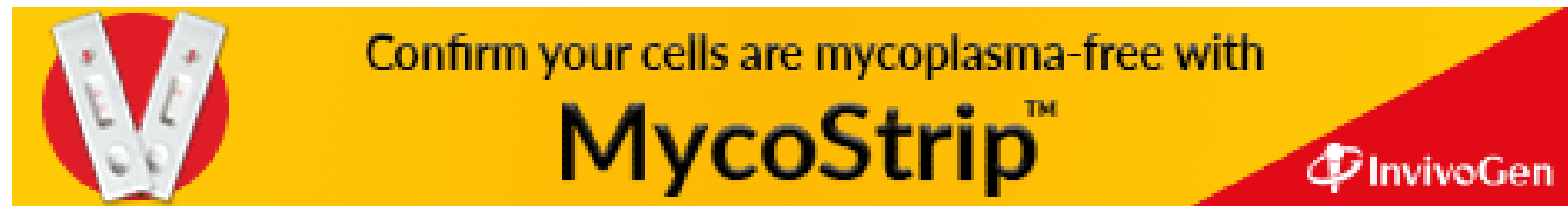

